Ciência e Natura, Santa Maria, v. 37 n. 3 set-dez. 2015, p. 808-820

Revista do Centro de Ciências Naturais e Exatas - UFSM

ISSN impressa: 0100-8307 ISSN on-line: 2179-46017326

\title{
ciênciaenatura
}

\section{Organização inicial de uma Ilha Interdisciplinar de Racionalidade a partir de um tema específico da biologia}

\author{
Initial Organization of Interdisciplinary Island Rationality from a specific topic of biology \\ Elenize Rangel Nicoletti, Lenira Maria Nunes Sepel
}

Universidade Federal de Santa Maria

\begin{abstract}
Resumo
Os vírus fazem parte dos conteúdos abordados nas aulas de biologia do ensino médio. Mas será que assuntos interessantes relacionados a este tema não estão ficando de lado por não terem tanta ligação com a biologia? Em vista disso, este trabalho investigou quais as potencialidades interdisciplinares desse temática para a sala de aula. Tomamos como referenciais de nossa pesquisa as metodologias: Abordagem Relacional e Ilhas Interdisciplinares de Racionalidade. Apresentamos algumas reflexões e possibilidades para organização inicial de um trabalho interdisciplinar relacionado a temática 'vírus' para o Ensino Médio. Constatamos que existem diversas possibilidades de atividades para as quatro áreas do conhecimento: Linguagem, Ciências da Natureza, Matemática e Ciências Humanas. A partir dessa abordagem inicial implementaremos uma Ilha de Racionalidade com alunos e professores do Ensino médio. Esperamos assim, contribuir para um ensino um pouco menos fragmentado, despertando o interesse $e$ participação dos alunos no processo de aprendizagem.
\end{abstract}

Palavras-chave: Ensino Médio, Vírus, Interdisciplinaridade, Ithas Interdisciplinares de Racionalidade, Abordagem Relacional.

\begin{abstract}
Viruses are part of the contents covered in high school biology classes. But is interesting topics related to this subject are not standing aside for not having as much connection with the biology? As a result, this study investigated which interdisciplinary potential of this issue for the classroom. We take as our benchmark research methodologies: Relational Approach and Interdisciplinary Islands Rationality. We present some thoughts and possibilities for initial organization of an interdisciplinary work related to the theme 'virus' to high school. We note that there are various activities possibilities for the four subject areas: Language, Natural Sciences, Mathematics and Humanities. From this initial approach we will implement a Rationality Island with students and middle school teachers. We hope to contribute to a school a little less fragmented, arousing the interest and participation of students in the learning process.
\end{abstract}

Keywords: High School, Virus, Interdisciplinary, Interdisciplinary Islands Rationality, Relational Approach. 


\section{Introdução}

I nterdisciplinaridade é um termo presente nos referenciais da educação brasileira e está em destaque há muito tempo. As Diretrizes Curriculares Nacionais para o Ensino Médio (DCN) publicadas em 1998 organizaram a base nacional para o ensino em três áreas de conhecimento e estabeleceram oficialmente a interdisciplinaridade e a contextualização como princípios pedagógicos estruturadores dos currículos (BRASIL, 1998).

Diversos autores apresentam concepções de interdisciplinaridade que convergem com as orientações oficiais, as quais criticam $\mathrm{o}$ conhecimento descontextualizado e fragmentado, sem diálogo entre as distintas áreas. Ainda, orientam que haja integração entre os diferentes conhecimentos, e que sejam destinados a resolver problemas vinculados à realidade social (PINHEIRO; WESTPHAL; PINHEIRO, 2007).

$\mathrm{O}$ texto dos Parâmetros Curriculares Nacionais para o Ensino Médio (PCNEM) de 2000, ao apresentar as principais características da reforma curricular proposta para o Ensino Médio, descreve a situação típica do ensino na época e indica a interdisciplinaridade como forma de superação do problema da segmentação do conhecimento:

A tendência atual, em todos os níveis de ensino, é analisar a realidade segmentada, sem desenvolver a compreensão dos múltiplos conhecimentos que se interpenetram e conformam determinados fenômenos. Para essa visão segmentada contribui o enfoque meramente disciplinar que, na nova proposta de reforma curricular, pretendemos superado pela perspectiva interdisciplinar e pela contextualização dos conhecimentos (BRASIL, 2000, p. 21).

A tentativa de aproximar áreas de conhecimento afins através da criação das áreas Ciências da Natureza, Matemática e suas Tecnologias; Linguagens, Códigos e suas Tecnologias e Ciências Humanas e suas Tecnologias porém não levou ao resultado esperado. Em 2010, a publicação de um estudo patrocinado pela Representação da UNESCO no Brasil concluiu que a interdisciplinaridade de fato, não chegou às salas de aula e revelou a partir de estudos de caso a realidade da maioria das escolas:

Observa-se que os ditames legais e normativos e as concepções teóricas, mesmo quando assumidas pelos órgãos centrais de uma secretaria estadual de educação, têm fraca ressonância nas escolas, e até mesmo pouca ou nenhuma na atuação dos professores (CASTRO; REGATTIERI; 2010, p.79).

As DCN Gerais para a Educação Básica, texto publicado em 2013, afirmam que a matriz curricular deve se organizar por "eixos temáticos". Nessa nova proposta, são os eixos temáticos que organizam a estrutura do trabalho pedagógico:

O trabalho com eixos temáticos permite a concretização da proposta de trabalho pedagógico centrada na visão interdisciplinar, pois facilita a organização dos assuntos, de forma ampla e abrangente, a problematização e o encadeamento lógico dos conteúdos e a abordagem selecionada para a análise e/ou descrição dos temas (Brasil, 2013, p.30).

Ainda sobre este documento, há destaque para a interdisciplinaridade e para a contextualização como aspectos para a organização da matriz curricular, as quais:

devem ser constantes em todo o currículo, propiciando a interlocução entre os diferentes campos do conhecimento e a transversalidade do conhecimento de diferentes disciplinas, bem como o estudo e o desenvolvimento de projetos referidos a temas concretos da realidade dos estudantes (BRASIL, 2013, p.34).

No que se refere especificamente ao Ensino Médio (EM), o parecer 5/2011 do Conselho Nacional de Educação que apresenta as DCN para o Ensino Médio reconhece em na sua introdução que o EM:

tem ocupado, nos últimos anos, um papel de destaque nas discussões sobre educação brasileira, pois sua estrutura, seus conteúdos, bem como suas 
condições atuais, estão longe de atender às necessidades dos estudantes, tanto nos aspectos da formação para a cidadania como para o mundo do trabalho (BRASIL, 2012, p. 1).

Dentre as possíveis soluções para melhorar a formação dos estudantes, as DCN Gerais para a Educação Básica destacam a necessidade de transversalidade entre os componentes curriculares, através da interdisciplinaridade e da contextualização:

a interdisciplinaridade e a contextualização devem assegurar a transversalidade do conhecimento de diferentes componentes curriculares, propiciando a interlocução entre os saberes e os diferentes campos do conhecimento (BRASIL, 2013, p. 68).

Segundo Araujo (2003) as disciplinas tradicionais não conseguem mais explicar a complexidade dos fenômenos atuais estudados, sendo necessária a utilização de temáticas, que perpassam a própria articulação entre as disciplinas. Ainda, ressalta que as temáticas devem estar relacionadas com melhorias na sociedade e com conflitos vividos pelas pessoas (ARAUJO, 2003).

Os planejamentos utilizando eixos temáticos podem ser uma forma de superar as dificuldades que limitam o ensino interdisciplinar e de trazer o ensino para o contexto da realidade vivenciada pelo aluno, especialmente no que se refere à educação em ciências Além disso, o ensino através de temática favorece o processo de ensino e aprendizagem e contribui para a formação do caráter cidadão dos alunos. (BRAIBANTE E PAZINATO, 2014). O desafio das propostas é fazer com que o aluno perceba que o conhecimento que é apresentado na escola serve para resolver problemas do seu dia-a-dia.

É importante destacar que um bom planejamento de atividades interdisciplinares, com encadeamento de conceitos entre áreas afins, não é suficiente para garantir sucesso na educação em ciência. Resultados significativos têm maior chance de ocorrer se os planejamentos conseguirem agregar de forma oportuna a dimensão conceitual do ensino de ciências à dimensão formativa e cultural, fazendo interagir a educação em ciência com a educação pela ciência (SANTOS, 1999).

Embora seja unânime o reconhecimento da importância das atividades interdisciplinares e do potencial que elas apresentam para que a escola cumpra o papel de contribuir com o desenvolvimento da criticidade dos alunos, a interdisciplinaridade ainda é um grande desafio. Frente à imensa diversidade de temas e conteúdos que podem ser explorados no EM e considerando o contexto escolar - especialmente o pouco tempo disponível para planejamentos, a carga horária dos professores associada ao número de alunos que devem ser atendidos - é compreensível que as atividades de ensino sigam modelos muito tradicionais Uma das principais limitações dos planejamentos de aula expositiva tradicional, baseadas apenas no livro didático é que este modelo não favorece o diálogo entre professor e aluno (COSTA BEBER, L.C.; KOGLER, J.T.S.; FRISON, M.D., 20014). Ainda, de acordo com o Guia do Programa Nacional do Livro Didático) o livro didático é uma das principais formas de documentação e consulta utilizada pelos professores e alunos, o que acaba influenciando o trabalho pedagógico $\mathrm{e} o$ cotidiano da sala de aula.

Um bom tema para abordagens interdisciplinares pode estar situado em uma disciplina específica, e tradicionalmente ser abordado sob forma de um tópico exclusivo no programa de uma série escolar. $\mathrm{O}$ reconhecimento de um tema com potencial interdisciplinar exige que se compreenda a importância das relações entre diversas áreas para resolver um problema. Ainda, necessita que seja realizado um exercício de construção de relações entre os conhecimentos das diversas áreas. As DCN para a Educação Básica apresentam que um dos passos para uma abordagem interdisciplinar e contextualizada é perceber a rede diversificada de relações com as diferentes áreas de conhecimento que um assunto apresenta (BRASIL, 2013).

A identificação das possibilidades de interações a partir de um determinado tema é um trabalho que exige, além do conhecimento específico de uma área, a exploração das diferentes dimensões que tangenciam um problema, uma situação ou uma informação. No presente trabalho apresentamos uma investigação das possibilidades de trabalho interdisciplinar usando o tema vírus.

Quais ligações podem ser estabelecidas entre os diferentes assuntos relacionados ao tema vírus e as disciplinas das diferentes áreas do EM? A 
partir desse questionamento, exploramos a organização de um trabalho interdisciplinar com este tema. Dentre as várias alternativas que podem conduzir a atividades interdisciplinares selecionamos a abordagem proposta por Fourez, as Ilhas Interdisciplinares de Racionalidade (IIR). Essa metodologia foi escolhida por acreditarmos que a interdisciplinaridade deve enfocar os problemas do cotidiano utilizando o maior número de disciplinas possíveis para resolvê-los, o que vai ao encontro com as ideias apresentadas pelo autor (FOUREZ, 1997).

O foco do nosso trabalho é a organização inicial da IIR, a etapa prévia durante a qual o professor se organiza, antes do contato com a sala de aula.

\section{Referencial Teórico}

\subsection{0 tema vírus}

Diariamente os noticiários abordam a importância dos vírus para a humanidade. Em 2014, viroses foram destaque em várias manchetes que destacavam, por exemplo, surtos de dengue em vários estados brasileiros, o alerta para entrada do vírus chikungunya no Brasil, campanhas de imunização desenvolvidas pelo Ministério da Saúde, os riscos de disseminação do vírus ebola da África para os outros continentes. Além do que aparece na mídia com o caráter de notícia, em geral apresentando novidades sobre esses temidos microorganismos, há uma grande quantidade de informações relacionadas às viroses que fazem parte do cotidiano das populações que não ganham manchetes ou divulgações especiais.

Os vírus estão no nosso dia a dia e várias decisões coletivas ou individuais podem ser orientadas por um melhor conhecimento dos assuntos relacionados a esses patógenos. A definição dos esquemas de vacinação, com os diferentes tipos de vacina e as faixas etárias para as quais estão disponíveis, é missão do Ministério da Saúde, mas a adesão às campanhas e realização das vacinações previstas como rotineiras dependem de como esse processo de imunização é compreendido pelas pessoas.

A existência dos vírus, no EM geralmente está restrita ao primeiro ano, quando os professores de biologia apresentam os diferentes tipos de organização dos seres vivos (vírus, procariontes e eucariontes). Porém, a partir do tema vírus é possível estabelecer conexões variadas e complexas com a qualidade de vida das populações, especialmente no que diz respeito à preservação da saúde, seja através da manutenção ou degradação das condições ambientais, seja através do entendimento de quais são as escolhas mais adequadas para evitar contágios ou para selecionar tratamentos.

Um dos papéis da escola é o desenvolvimento da criticidade dos alunos, ou seja, formar cidadãos críticos e capazes de tomar iniciativas a respeito de assuntos variados (BRASIL 1998; 2000). Se em determinada região de nosso país está ocorrendo um surto de alguma doença, nossos alunos precisam dominar um mínimo de conhecimentos para sua proteção e diminuição de riscos de contágio de sua comunidade. Para isso, além da informação, o aluno precisa saber usá-la, tendo um posicionamento crítico.

Os PCN para o Ensino Médio (BRASIL, 2000) orientam, em seus objetivos, que devemos trabalhar a formação individual do aluno, bem como o desenvolvimento de valores e competências necessárias que o integrem no projeto da sociedade em que se situa. Ainda, as Leis de Diretrizes e Bases para a Educação (LDB) afirmam que uma das finalidades do EM é "o aprimoramento do educando como pessoa humana, incluindo a formação ética e o desenvolvimento da autonomia intelectual e do pensamento crítico" (BRASIL, 1996).

O desenvolvimento da cidadania responsável (individual e social) depende do estímulo que é dado para que os alunos lidem com problemas que tem dimensão científica (SANTOS, 1999). Por exemplo, professor está apresentando a ciência que está associada a uma patologia quando discute em suas aulas os vetores de uma doença viral, os métodos de transmissão, o tratamento e a prevenção. O professor que educa para a cidania, compreende que o aluno possui o direito, enquanto sujeito escolar, a adquirir conhecimento para tomar atitudes conscientes que beneficiem toda comunidade. A educação é um instrumento social básico, que possibilita ao estudante realizar uma transposição, da marginaliade para a materialidade da cidadania (MARTINS, 2001).

Pensando em situações concretas - uma escola localizada num bairro onde foram encontrados focos de larvas de mosquito da dengue - o que o 
professor poderá fazer para colaborar? Uma possibilidade seria levantar as concepções dos alunos sobre a situação, fazendo um questionamento inicial para compreender as ideias presentes acerca do assunto. Na sequência, surgem os planejamentos que podem interferir na situação - poderia ser organizado um passeio no bairro, associado a explicações sobre os métodos de prevenção, transmissão e sintomas da dengue e, ao retornar a sala de aula, discussão e sistematização de informações. Em relação aos resultados sobre práticas, usos e costumes, poderíamos esperar que tal conjunto de atividades desenvolvesse atitudes mais conscientes (evitar deixar água parada em vasos de plantas, fiscalizar terrenos na comunidade em busca de latas e pneus). Em uma situação como essa, também é esperado que os alunos cumpram papel na difusão de informação explicando aos familiares e vizinhos os conhecimentos apreendidos.

Situações concretas podem ser abordadas de diferentes modos, seja através de planejamentos espontâneos decorrentes da experiência dos professores, como no exemplo do parágrafo anterior, seja por metodologias que envolvem maior ou menor complexidade. Dentre as metodologias mais estruturadas podemos citar o Arco de Marguerez (BERBEL, 1998) e a Resolução de Problemas como investigação científica (GIL PÉREZ et.al, 1992).

As abordagens que usam problemas concretos para o ensino de ciências tentam agregar de forma oportuna a dimensão conceitual à dimensão formativa e cultural, fazendo interagir a educação em ciência com a educação pela ciência (SANTOS, 1999). Nessas propostas, o aluno tem a possibilidade de perceber que o conhecimento transmitido em aula pode ser útil para resolver problemas do seu dia-a-dia. Por isso, é recomendável partir de propostas que envolvem o aluno em assuntos atuais e permitem conjugar os conteúdos clássicos numa abordagem que extrapola a dimensão meramente conceitual, trazendo para sala de aula problemas de interesse social (TEIXEIRA, 2003).

De que modo a escola pode contribuir para a aprendizagem crítica, com importância social e que contribua para a cidadania usando um tema específico como vírus? Com base nesse questionamento, apresentamos algumas reflexões e possibilidades de trabalho interdisciplinar da temática 'vírus' para o EM. Tomamos como referenciais nesse trabalho as Ilhas Interdisciplinares de Racionalidade (FOUREZ, 1997) e Abordagem Relacional (MORAES, 2001). A ideia central desta proposta é explorar o maior número de atividades possíveis acerca de um tema específico da biologia. Acreditamos que esse exercício exploratório pode aumentar a possibilidade de professores de outras disciplinas encontrarem dentro do tema pontos que podem ser explorados sob forma de conteúdos disciplinares ou através de atividades integradas.

\subsection{Ilhas Interdisciplinares de Racionalidade}

A escola apresenta o conhecimento dividido em disciplinas. No entanto, Fourez (1998) sugere que seja discutida, no âmbito escolar, uma nova estrutura curricular. $\mathrm{O}$ autor orienta que os conhecimentos sejam baseados em projetos, os quais incluam ideias das diversas áreas de conhecimentos estudadas e também do senso comum do estudante. Segundo o autor, através de um projeto é possível construir representações para situações concretas, embasadas numa metodologia a qual intitula Ilhas de Racionalidade (FOUREZ, 1997).

Fourez desenvolve a ideia de Ilha de Racionalidade (IR) usando como apoio uma metáfora com objetivo de dar evidência a alguns aspectos que outros termos técnicos não destacam $^{1}$ No artigo publicado em 1997, na revista Aster (Institut National de Recherche, França), Fourez se preocupa em apresentar o que uma IR não é. Nesse mesmo artigo, o autor destaca que o tipo de representação proposta por ele pode ser chamada de IR por várias razões e cita a metáfora inicial em torno da qual o conceito foi construído: "uma ilha em meio a um oceano de ignorância"(FOUREZ, 1997b).

A construção de IR, segundo Fourez, é a forma através da qual organizamos as informações disponíveis e a criação dessa representação faz parte dos processos rotineiros

1Citação original: “Comme toute nouvelle notion, celle d'îlot de rationalité part d'une métaphore et vise à mettre en évidence des aspects que d'autres termes techniques laissent davantage dans l'ombre." 
de avaliação de situações complexas. Para reforçar essa ideia, o autor cita exemplos de situações profissionais e familiares onde uma representação do tipo IR é espontaneamente utilizada (Fourez, 1997b).

No ensino, a IR deve buscar solucionar problemas relacionados ao cotidiano do aluno, baseando-se na construção de modelos derivados de uma situação concreta. A representação através de IR deve trazer uma melhor compreensão e capacidade de decisão frente a uma situação complexa. Quando as IR são produzidas para situações de ensino, é interessante que as questões sejam abordadas sob o ponto de vista de saberes disciplinares específicos. Nesse caso, trata-se da construção de uma representação interdisciplinar, correspondendo ao um tipo de especial de IR, a Ilha Interdisciplinar de Racionalidade (IIR).

Fourez denominou de "caixas pretas" as questões que surgem durante a construção de uma IR. Ao se construir uma IIR questões específicas ligadas a determinados conhecimentos disciplinares surgirão e poderão ser respondidas ou não, dependendo do objetivo inicial. A abertura de uma caixa preta "significa a obtenção de modelos que possam relacionar os fatos conhecidos, gerando explicações" (NEHRING et al., 2002).

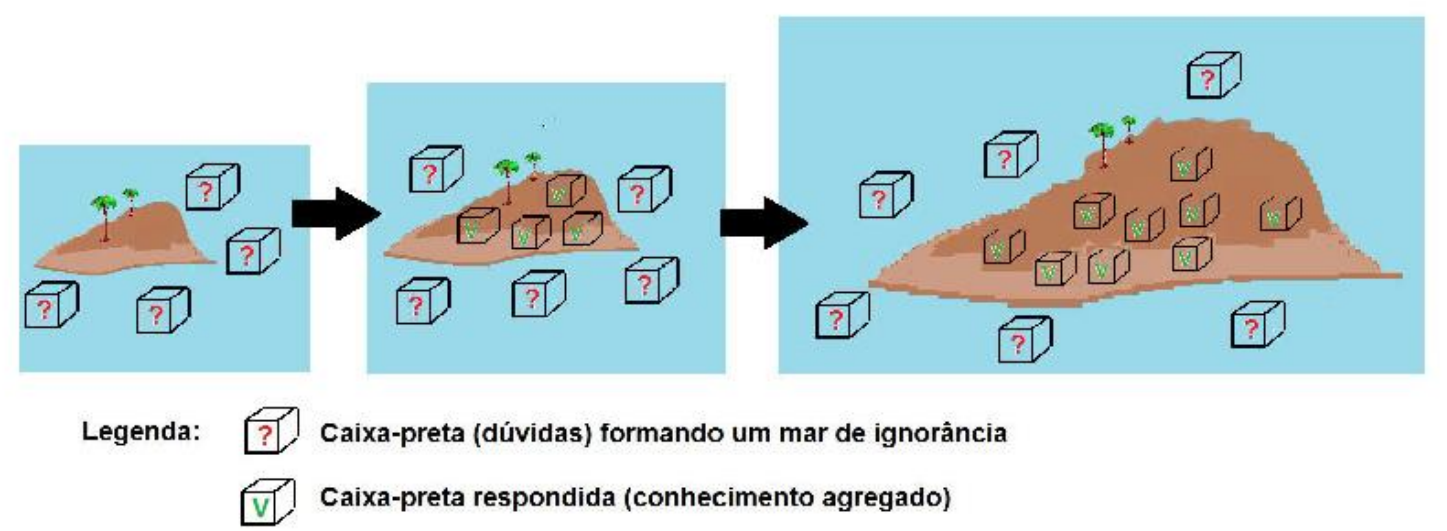

Figura 1: Analogia do nosso conhecimento (ilha) em um mar de dúvidas, segundo Fourez.

Fonte: autoras

A analogia usada por Fourez pode ser interpretada e desenvolvida sob diferentes perspectivas. Consideramos aqui que a noção de ilha se ajusta ao conhecimento que o indivíduo possui e sobre o qual tem domínio - seria a terra firme disponível. Ao analisar uma questão complexa, especialmente as que se relacionam aos conhecimentos de ciência e tecnologia, o indivíduo pode sentir-se incapaz de usar as informações disponíveis que poderiam ser úteis para resolver um problema ou amparar uma decisão. Nesse momento, visualizamos o oceano de ignorância. Construindo a continuidade dessa analogia, as caixas pretas seriam as informações que o indivíduo sabe que podem existir, mas sobre as quais não tem domínio, apenas dúvidas. Nessa interpretação, o oceano de ignorância pode ser transformado em um conjunto de caixas pretas. Quantas e quais caixas pretas serão abertas depende do interesse de quem constrói a IR e do objetivo da construção. De que modo as caixas pretas serão abertas dependerá da disponibilidade de acesso à informação, sendo a consulta aos especialistas da área uma das formas. É possível estender a metáfora e criar a analogia do crescimento de uma ilha e o desenvolvimento do conhecimento. O território de uma ilha pode crescer por deposição de materiais, o conhecimento se expande à medida em que as caixas pretas são abertas. A abertura de uma caixa corresponde tanto a aquisição de novos conhecimentos quanto ao aprofundamento de informações. Nessa comparação, as IR, sendo representações, não crescem territorialmente, mas permitem a ampliação do conhecimento. Se o conhecimento for considerado semelhante ao território de uma ilha, é possível antever que a construção de IIRs a partir de situações concretas que sejam semelhantes ou vinculadas ao mesmo tipo de problema, levará a uma expansão progressiva do conjunto de informações, reduzindo o espaço ocupado pelo "oceano de ignorância". É com base nessa imagem que valorizamos as IIR. 
Quando as situações problema geram caixas pretas relacionadas a vários saberes disciplinares cria-se a possibilidade de ampliação do conhecimento de modo integrado e dinâmico. Além disso, há sempre a chance de que a abertura de uma caixa preta de uma IIR crie novas questões levando ao aprofundamento dos saberes e ao desenvolvimento de novos interesses.

A construção de uma IIR proporciona aos indivíduos participantes comunicação e atuação utilizando conhecimentos oriundos de diversas disciplinas e, também, dos saberes da vida cotidiana. A criação do modelo para a situação estudada implica em uma articulação entre conhecimentos científicos que são veiculados pelas disciplinas escolares e do cotidiano dos alunos é abordada por Fourez (1997) como Alfabetização Científica e Tecnológica (ACT).
Eu consideraria alguém como alfabetizado científica e tecnologicamente quando seus saberes permitem uma certa autonomia (possibilidade de negociar suas decisões frente às pressões naturais ou sociais), uma certa capacidade de comunicação (encontrar as maneiras de dizer), e um certo domínio e responsabilidade, frente a situações concretas (FOUREZ, 1997, p.62).

Usar a metodologia das IIR é uma tentativa de melhorar a alfabetização técnica e cientifica. A proposta baseia-se em oito etapas. e cabe ao professor decidir, de acordo com o tema escolhido se realizará todas as estapas sugeridas, podendo suprimir e também agrupar as que classificar como semelhantes.

No quadro 1 descrevemos brevemente as etapas da IIR.

Quadro1- Resumo das etapas de uma Ilha Interdisciplinar de Racionalidade.

\begin{tabular}{|l|l|}
\hline 0) Organização da Ilha & $\begin{array}{l}\text { Esta etapa refere-se ao preparo prévio do professor. Neste momento devem ser } \\
\text { levantados os possíveis assuntos envolvidos na temática escolhida; os } \\
\text { materiais e ambientes da escola que serão utilizados; alguns especialistas que } \\
\text { poderão ser consultados, etc. }\end{array}$ \\
\hline 1) Clichê & $\begin{array}{l}\text { Levantamento das concepções, interesses e curiosidades dos estudantes sobre } \\
\text { o tema. }\end{array}$ \\
\hline 2) Panorama espontâneo & $\begin{array}{l}\text { Momento de expandir as ideias levantadas na primeira etapa e organizar as } \\
\text { próximas etapas. }\end{array}$ \\
\hline 3) Consulta a especialistas & Definição das especialidades consultadas pela turma. \\
\hline 4) Indo a campo & $\begin{array}{l}\text { Realização de entrevistas e pesquisas para aprofundar os conhecimentos dos } \\
\text { alunos. }\end{array}$ \\
\hline $\begin{array}{l}\text { 5) Abertura de caixas pretas } \\
\text { com ajuda de especialistas }\end{array}$ & $\begin{array}{l}\text { Neste momento entram os especialistas envolvidos, que podem ser professores } \\
\text { de outras disciplinas, médicos, enfermeiros, assistente social, etc. }\end{array}$ \\
\hline 6) Esquema global & $\begin{array}{l}\text { Aproxima-se com uma síntese parcial do que já foi feito e o que ainda falta } \\
\text { fazer para o andamento do projeto. }\end{array}$ \\
\hline $\begin{array}{l}\text { 7) Abertura de caixas pretas } \\
\text { sem a ajuda de especialistas }\end{array}$ & $\begin{array}{l}\text { Momento de autonomia dos estudantes, eles ficam responsáveis pela resolução } \\
\text { de questões da ilha, sem ajuda de especialistas. }\end{array}$ \\
\hline 8) Síntese da IIR & $\begin{array}{l}\text { Etapa para sintetizar tudo que foi trabalhado. Sugestões: produção de um } \\
\text { vídeo coletivo, uma página na internet, um jornal para a escola, a construção } \\
\text { coletiva de um texto, etc. }\end{array}$ \\
\hline
\end{tabular}

Fonte: autoras

Para que uma IIR fique bem organizada é necessário que o professor esquematize tudo o que é possível ser trabalhado acerca do tema que escolher. A própria escolha do tema é algo a ser pensada, ela poderá surgir de uma necessidade local do município, da comunidade onde a escola está inserida ou até mesmo uma particularidade da própria urma. Para tanto, faz-se necessário um levantamento prévio das atividades pelo professor. Vários autores apontam a importância dessa etapa, descrita como 'etapa zero' da metodologia (Pinheiro et al. ,2000; Pietrocola, Pinho-Alves e Pinheiro, 2003; Nehring et al., 2002; Bettanin; 2003; Schmitz, 2004).

Neste trabalho destacaremos a importância da etapa zero, a qual o professor realiza antes de 
ir para a escola aplicar a metodologia IIR. Esse momento do trabalho é muito importante para a organização do trabalho docente, pois é o período onde objetiva-se: verificar condições de aplicabilidade do projeto, a questão tempo, técnicas a serem adotadas, material didático necessário, recursos humanos, fontes de informação, quando e como realizar a avaliação (SCHMITZ, 2004).

Existem várias possibilidades de organização inicial das ideias que o professor pode utilizar para construir uma IIR, entre eles estão os organogramas, os mapas conceituais e os esquemas relacionais. Os organogramas são comumente usados em empresas e voltados a trabalhos administrativos, pois geralmente estão baseados em um sistema hierárquico (CHIAVENATO, 2001). Os mapas conceituais são diagramas de significados, de relações significativas; de hierarquias conceituais (MOREIRA, 2006). Segundo o autor, essa metodologia comumente utilizada no ensino, pode ser utilizada como instrumento de avaliação da aprendizagem, para se obter uma visualização da organização conceitual que o aprendiz atribui a um dado conhecimento.

Os esquemas relacionais partem de uma Abordagem Relacional, e são fundamentados em ações pedagógicas baseadas no estudo das relações. É elaborado considerando a complexa rede de conexões entre determinado assunto (MORAES, 2003).

\subsection{Esquemas Relacionais}

Segundo Moraes e Colombi (2004) a Abordagem Relacional apresenta-se como uma proposta educacional preocupada com a criação de condições que permitam as pessoas perceberem, compreenderem e aprenderem sobre diferentes visões de mundo além daquela apresentada pela escola. Os autores afirmam que a partir de uma visão expandida de um tema qualquer é possível que o ser humano perceba-se integrante à humanidade. Ou seja, conhecer as diversas possibilidades de um determinado assunto deve:

permitir aos seres humanos reconhecer o seu pertencimento (condição de ser integrante) à humanidade (conjunto de seres humanos que existiram, existem e existirão) e ao planeta em que vivemos (MORAES; COLOMBI, 2004).
Expandir as possibilidades de ligações e interrelações dentro de uma tema torna-se muito importante, a medida que se não houver uma variabilidade de conhecimentos disponíveis o aluno ficará a mercê das mesmas soluções prontas. Corre-se o risco de formarmos um círculo vicioso entre problema e solução, instalando-se um sentimento de impotência frente à tomada de decisão (MORAES; COLOMBI, 2004).

Este tipo de metodologia permite a construção de esquemas relacionais, conforme podemos ver na figura 2. Analisando essa figura, podemos ver que há um tema principal e deles partem outros assuntos relacionados. O tema inicial é o único determinado e dele emergem vários sub-temas, que podem ou não ter relações entre si. É importante ressaltar que em se tratando de uma sala de aula, cada estudante pode fazer relações individuais acerca de um tema. Conforme afirmam Moraes e Colombi (2004) 'cada ser possui uma dimensão relacional própria e, portanto ele pode ser identificado pela sua capacidade para se relacionar'. Porém, é possível que após um levantamento individual de ideias seja feita uma construção de um esquema coletivo.

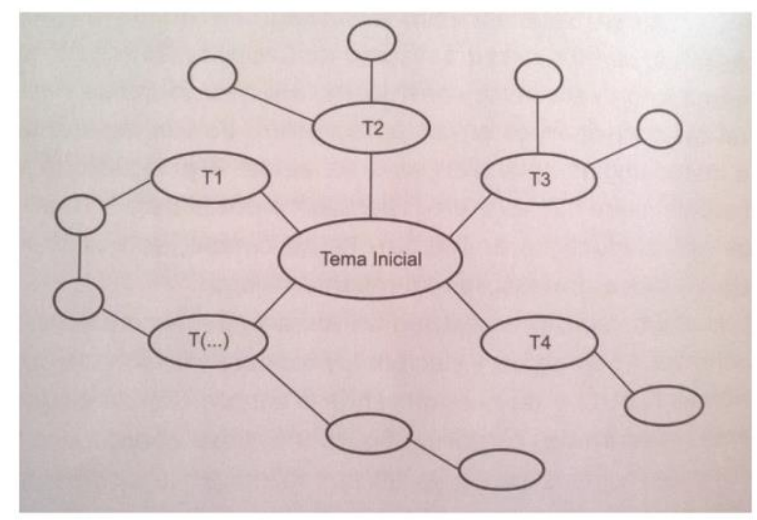

Figura 2: Modelo de Esquema relacional proposto por Moraes (2001).

O mapeamento inicial das ideias de uma turma proporcionará ao professor uma ideia geral da visão de mundo daquele grupo. Esse formato de intervenção permite discussões acerca de como nosso conhecimento é influenciado pela cultura, e que nossas ideias geralmente partem de um coletivo comum (sociedade). Como afirmam Boer e Moraes (2006), "as visões de mundo estão ligadas a uma civilização específica e a uma determinada época 
e, mesmo sendo individuais, são construídas coletivamente".

No ambiente escolar torna-se necessário trabalhar essas ligações entre o que queremos ensinar e o cotidiano, de forma a permitir uma visão mais generalizada dos assuntos.

A construção de Esquemas Relacionais (MORAES, 2001) permite expandir nossa visão sobre determinado assunto. Bem como a metodologia proposta por Fourez (1997b), a qual proporciona ao professor partir de um conceito bem restrito para noções mais amplas de temas que considere interessante.

Baseados nesses conhecimentos e após levantarmos grande número de possibilidades para trabalhar o tema vírus no EM, montamos um esquema relacional que organizasse e apresentasse nossas ideias. Ele norteará a construção de uma IIR com estudantes e professores e foi organizado assim, por consideramos um bom formato de apresentação inicial de ideias.

As metodologias descritas não são iguais, mas possuem similaridades e nos permitem associações. Ambas partem de uma técnica conhecida como 'brainstorming', que em português significa 'tempestade de ideias'. Também pretendem expandir as visões do estudante sobre determinado assunto, proporcionando que enxerguem relações entre os temas estudados e o seu cotidiano. Acreditamos que partir de um Esquema Relacional sobre os Vírus para a construção de uma IIR sobre o tema nos possibilitará uma visão bem ampla do que seja possível estudar acerca dessa temática e através das relações analisarmos seu potencial interdisciplinar.

\section{$3 \mathrm{O}$ potencial interdisciplinar do tema Vírus}

O currículo brasileiro é organizado por quatro áreas do conhecimento: Linguagens; Matemática; Ciências da Natureza; Ciências Humanas (Brasil, 2012). Segundo as Novas Diretrizes Curriculares da Educação essa organização não exclui componentes curriculares, pois estes possuem saberes próprios construídos e sistematizados, "mas implica no fortalecimento das relações entre eles e a sua contextualização para apreensão e intervenção na realidade, requerendo planejamento e execução conjugados e cooperativos dos seus professores" (BRASIL, 2012).

Em relação a temática dos vírus, verificamos nos PCNEM a orientação de trabalhar noções de como operam os níveis submicroscópicos da biologia para compreender a biotecnologia e a forma como certos vírus produzem imunodeficiências (BRASIL, 2000). Já nas Orientações Educacionais Complementares aos Parâmetros Curriculares Nacionais (PNCEM+) verificamos uma maior inclusão de sugestões sobre o tema. Inicialmente é sugerido dentro do tema 'Qualidade de vida das populações humanas' que sejam discutidos dados de incidência das DST, particularmente a Aids, em nosso país. Em seguida, aparecem as relações entre dengue, degradação ambiental e a ocupação desordenada dos espaços urbanos. Por fim, associam os vírus com fatores ambientais que aumentam o risco de desenvolver câncer e medidas que podem reduzir esses riscos (BRASIL, 2002).

Podemos ver que há uma preocupação nos documentos oficiais de que o professor trabalhe as principais doenças virais, associando problemas ambientais ao aumento de vetores de alguns vírus e também a relação deles com a biotecnologia. Partindo dessas premissas, elaboramos um Esquema Relacional com possíveis relações entre esses assuntos.

Na figura 2 temos os vírus como tema central, de onde se ramificam três principais eixos: biologia, sociedade e economia. Optamos por desenvolver melhor os dois últimos, e fizemos associações entre biologia e alfabetização científica, que são as informações necessárias para um cidadão tomar decisões que envolvam sua saúde e a de toda comunidade.

O eixo sociedade está relacionado com a qualidade de vida do indivíduo, o qual dependerá de fatores como lazer, alimentação, trabalho, transporte, saneamento, nível de informação, etc. Todos esses ítens estão relacionados a temática dos vírus. Por exemplo, o meio de transporte que a pessoa utiliza influenciará nos cuidados com sua higiene, que está relacionado com seu nível de informação. Se a pessoa estiver gripada, é importante que leve a mão à boca ao espirrar, ainda mais se estiver utilizando transporte coletivo. Mesmo que essa pessoa estiver com a saúde em dia é interessante que carregue álcool gel na bolsa para usar após 
sair do veículo e assim evitar a contaminação por viroses.

Quanto mais esclarecida a pessoa for mais conseguirá fazer escolhas em benefício de suas saúde e da sociedade. Pensando nas condições de higiene, uma pessoa que souber que o mosquito da dengue coloca ovos em água parada, evitará jogar lixo em seu pátio ou terrenos baldios.

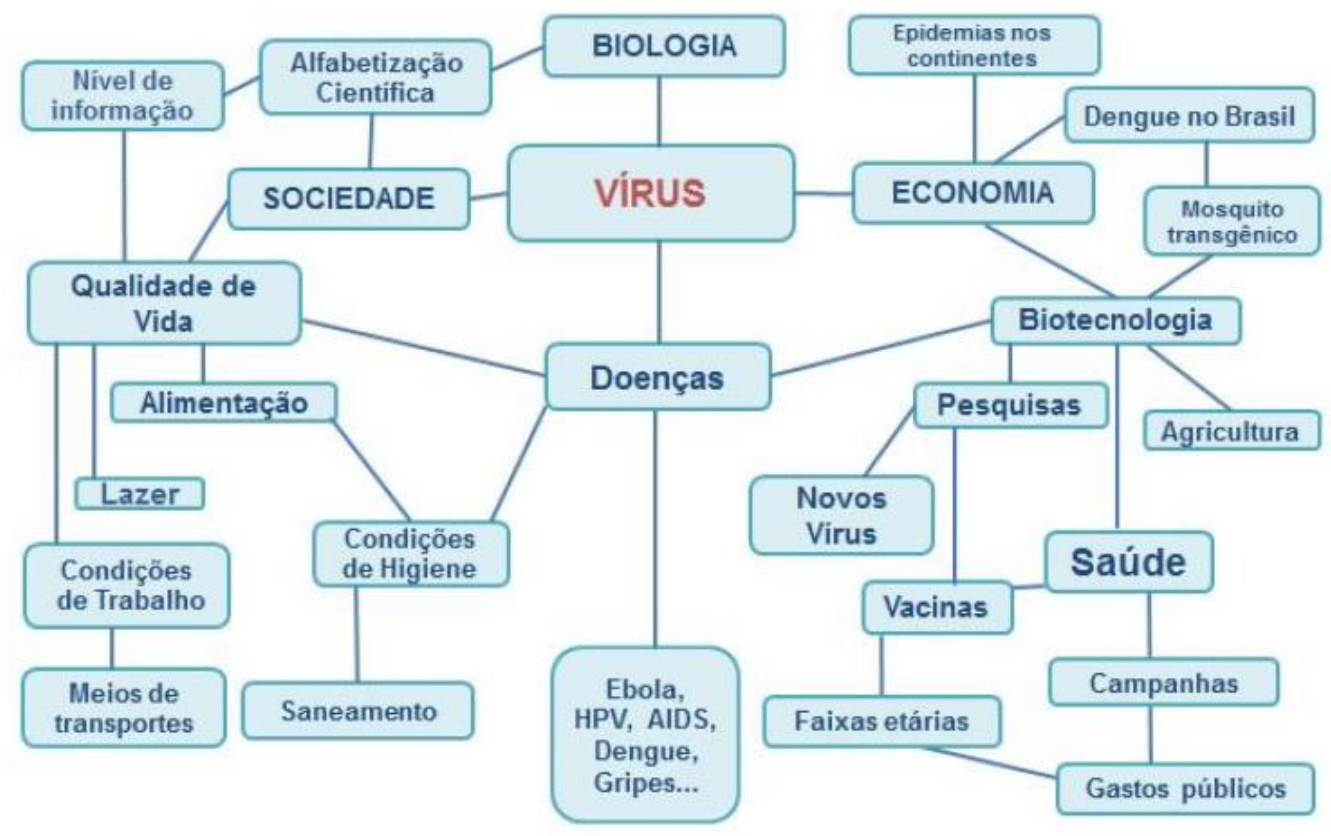

Figura 2: Esquema Relacional demostrativo da potencialidade interdisciplinar do tema Vírus Fonte: autoras

Em relação as doenças que podem ser abordadas citamos apenas o ebola, a Aids, a dengue, o HPV e as gripes. Porém não podemos esquecer que existem muitas outras, os resfriados, caxumba, raiva, rubéola, sarampo, as hepatites, poliomielite, febre amarela, herpes, entre outras.

Em relação ao sub-tema Economia podemos abordar os impactos das epidemias nos continentes, as pesquisas relacionadas a biotecnologia, como o desenvolvimento de mosquitos transgênicos. Estes, recebem DNA para produção de genes produtores de proteínas que impedem os descendentes de chegarem a fase adulta, e assim não consigam se reproduzir. Que impacto econômico essa descoberta traz? Diminuição dos gastos públicos com tratamentos de infectados e diminuição de campanhas contra dengue. Consequentemente $\mathrm{o}$ dinheiro economizado poderia ser utilizado em novas pesquisas, para a descoberta de medicamentos.

Por que não existe prevenção para alguns vírus como o HIV e o ebola? Por que as meninas de dez anos estão recebendo imunização para o HPV no Brasil? Por que nem todo vírus é transmitido da mesma forma, uns são pelo ar e água, outros apenas por secreções. Na história, quais foram as grandes epidemias que dizimaram populações? Existem armas biológicas? Essas e outras inúmeras questões emergem a partir da reflexão da figura 2. $\mathrm{O}$ ponto de vista do professor influenciará no seu preparo, bem como na abordagem que será feita no decorrer da Ilha.

Se pensarmos em algumas abordagens específicas para disciplinas surgem novas ideias. $\mathrm{Na}$ figura 3 podemos visualisar algumas propostas para as quatro áreas de conhecimento acerca dos vírus.

$\mathrm{Na}$ área da Matemática e suas tecnologias podemos trabalhar gráficos e estatísticas de muitas doenças. Também podemos calcular porcentagens de gastos com medicamentos. Vejamos um exemplo: uma determinada vacina é distribuida gratuitamente para crianças de $0 \mathrm{a}$ 5 anos. Quanto o governo precisaria dispor 
financeiramente se a vacinação fosse estendida para crianças de até 10 anos? O professor poderá solicitar que os alunos pesquisem que vacina é essa, que doenças ela previne, quantas crianças são beneficiadas, qual o gasto do governo, qual o número de indivíduos nas faixas de idade mencionadas em nosso país, etc. Após os alunos fazem os cálculos solicitados. Além disso, tem a oportunidade de trabalhar um assunto de interesse social nas aulas de matemática.
- Gráficos de distribuição de viroses no mundo;

- Dados estatísticos de epidemias;

- Tratamento de dados:

- Cálculo de valores gastos com tratamento de infectados.

- Vírus como arma biológica;

- Relação entre problemas ambientais e doenças virais:

- Vetores das viroses;

- A química das vacinas virais:

\section{Natureza}

Matemática

\section{Linguagens}

Analisar cartazes de prevenção de viroses

- Discutir reportagens sobre doenças virais:

- Montar maquete de vírus atacando uma célula.

- Trabalhar sobre um filme ou documentário que fale sobre vírus.

\section{VÍRUS}

\section{Humanas}

- O papel da ásia no surgimento das gripes:

- ARevolta da Vacina;

- Impacto econômico das viroses sobre a produção agrícola $\mathrm{e}$ pecuária

- Vírus são seres vivos?

Figura 3: Sugestões de assuntos para trabalhar no EM acerca da temática dos vírus nas diferentes áreas do conhecimento. Fonte: autoras

A área de Ciências da natureza e suas tecnologias é a que compreende o maior número de possibilidades de planejamentos. Nas aulas de biologia é possível trabalhar tópicos em citologia, biodiversidade, ecologia e genética. As aulas de química podem abordar a composição das vacinas. Se pegarmos o caso da vacina da gripe, o professor poderá discutir como é feita a fabricação nos diferentes hemisférios. Devido a época de ocorrência do inverno ser diferente no norte e no sul, é necessário investigar quais os vírus mais infectaram pessoas no último inverno. Consequentemente se os invernos ocorrem em épocas distintas, as espécies de vírus, e a composição da vacina também serão diferentes.

Em Linguagens e suas tecnologias é possível trabalhar com filmes que tratem a temática; leitura de reportagens de divulgação científica; construção de modelos de vírus infectando uma célula; utilização de vídeos e cartazes de campanhas, etc. Um trabalho interessante, e que pode ser feito com a ajuda de professores de outras disciplinas é o desenvolvimento de folders informativos a repeito de alguma virose de interesse da turma. Esse material pode ser construído também com ajuda de computadores e assim alcançar um público maior.

$\mathrm{Na}$ área das Ciências Humanas e suas tecnologias importantes relações podem ser feitas. Durante as aulas de história o professor pode abordar os verdadeiros motivos da população ter se rebelado contra a vacinação que protegia de varíola, período conhecido como Revolta da Vacina. A importância da Ásia e das aves na distribuição das gripes e o motivo de muitos vírus surgirem na África são bons tópicos para discussão nas aulas de geografia. Ainda, em Filosofia, é possível discutir o que é vida, partindo do princípio que vírus não são seres vivos.

Elencamos apenas três ou quatro exemplos para cada área do conhecimento, mas as opções são inúmeras e podem variar de acordo com as relações e vivências que cada um consegue fazer. 


\section{Conclusões e perspectivas}

Analisamos o potencial interdisciplinar de um tema específico da biologia - os vírus - e apresentamos um resumo de possíveis abordagens para o EM.

O método escolhido para apresentação, os Esquemas Relacionais, demostrou ser uma boa forma de organizar a etapa zero de uma IIR.

Os vírus, mesmo sendo um conteúdo específico da Biologia, apresentam capacidade de se relacionar com temas de Ciência, Tecnologia e Sociedade e serem utilizados em aulas associados ao contexto escolhido.

É possível que os professores de várias disciplinas abordem os vírus conforme as habilidades que as suas áreas requerem. Não pretendemos que todos os professores trabalhem esse tema em todas as suas aulas, durante todo o ano letivo. Mas buscamos através deste trabalho apresentar possibilidades, para que de acordo com sua realidade, cada professor faça seu planejamento.

A associação das duas metodologias (esquemas e ilhas) mostrou que é possível ao professor de biologia analisar as potencialidades interdisciplinares de temas do seu interesse. Ainda, enxergar associações entre disciplinas e planejar trabalhos conjuntos com os colegas.

\section{Referências}

ARAUJO, U.F. Temas Transversais e a estratégia de projetos. São Paulo:Editora Moderna, 2003.

BERBEL, N. A. N. Metodologia da problematização: experiências com questões de ensino superior. Londrina: EDUEL, 1998.

BETTANIN, E. As ilhas de racionalidade na promoção dos objetivos da alfabetização científica e técnica. Dissertação (Mestrado em Educação), CED, Universidade Federal de Santa Catarina, Florianópolis- SC, 2003

BOER, N.; MORAES, E. C. Políticas educacionais, visões de mundo e a articulação em processos educativos. Ciência \& Educação, Vol. 12, núm. 3, pág. 291-302, 2006.
BRAIBANTE, M.E.F.; PAZINATO, M.S. O Ensino de Química através de temáticas: contribuições do LAEQUI para a área Revista Ciência e Natura, Santa Maria, v. 36 Ed. Especial II, 2014, p. 819-826.

BRASIL. Lei 9394/96. Lei de diretrizes e bases da educação nacional. Brasília, 1996.

. Conselho Nacional de Educação (CNE). Resolução n. 3, de 26 de junho de 1998. Institui as Diretrizes Curriculares Nacionais para o Ensino Médio. Diário Oficial da República Federativa do Brasil, Brasília, DF, 5 ago. 1998.

Ministério da Educação. Secretaria de Educação Média e Tecnológica. Parâmetros Curriculares Nacionais (Ensino Médio). Brasília: MEC, 2000.

Ministério da Educação. Secretaria da Educação Média e Tecnológica. Parâmetros Curriculares Nacionais + $(\mathrm{PCN}+)-$ Ciências da Natureza e suas Tecnologias. Brasília: MEC, 2002.

Guia do Programa Nacional do Livro Didático . Secretaria da Educação Básica. Guia de Livros didáticos Programa Nacional do Livro Didático (PNLD). Brasília: MEC/SEF, 2008.

Conselho Nacional de Educação Câmara de Educação Básica. Diretrizes Curriculares Nacionais para o Ensino Médio. Parecer CNE/CEB n. 5/2011. Brasília, 2011. DOU de 24 de jan. 2012, Seção 1, p. 10.

Conselho Nacional de Educação, Câmara de Educação Básica. Diretrizes Curriculares Nacionais Gerais para a Educação Básica. Brasília, DF, 2013.

CASTRO, Jane M.; REGATTIERI, Marilza (orgs.). Interação Escola - Família: Subsídios para práticas escolares. Brasília: UNESCO, MEC, 2010.

CHIAVENATO, Idalberto. Teoria Geral da Administração. Rio de Janeiro: Campus, 2001. 
COSTA BEBER, L.C.; KOGLER, J.T.S.; FRISON, M.D. $\mathrm{O}$ ensino e a formação escolar: algumas implicações de modelos de ensino vivenciados em processos educativos. Revista da SBENBIO. Volume 5, número.7, outubro 2014.

FOUREZ, G, et al Alfabetización científica $y$ tecnológica. Acerca de las finalidades de la enseñanza de las ciencias. Buenos Aires, Argentina: Ediciones Colihue, 1997.

FOUREZ, G. Qu'entendre par 'îlot de rationalité' et par 'îlot interdisciplinaire de rationalité, In revue Aster, n²5, 1997b. Disponível em: http://ife.enslyon.fr/publications/editionelectronique/aster/RA025-10.pdf

FOUREZ, G. Pour une interdisciplinarité concrète et rigoureuse. Conférence sur l'interdisciplinarité pour des infirmiers, 1998.

GIL PÉREZ, Daniel; et al. 'Questionando a didática de resolução de problemas: elaboração de um modelo alternativo.' In: Caderno Catarinense de Ensino de Física, Florianópolis/BRA, UFSC, v.09 n.01, p.07-19, 1992.

MARTINS, R. B. Educação para cidadania: o projeto político-pedagógico como articulador. In: VEIGA, I. P. A.; REZENDE, L. M. G. de. Escola: espaço do projeto político-pedagógico. 4. Campinas: Papirus, 2001. cap. 3, p. 49-73.

MORAES, E. C. Ações Pedagógicas Relacionais. Texto de base para o curso de formação continuada para professores da Escola Básica José Boiteux. Laboratório de Pesquisa para um conhecimento integrado. Florianópolis: CCB/UFSC, 2001.

MORAES, E. C. Abordagem relacional:uma estratégia pedagógica para a educação científica na construção de um conhecimento integrado. In: ENPEC, 2003. Baruru, SP. Anais do evento: ABRAPEC, 2003. 1 CD-ROM.

MORAES, E. C.; COLOMBI, A. N. K. Sustentabilidade e educação biológica: Uma perspectiva relacional. In: Conferência Internacional de Educação Biológica, Desenvolvimento Sustentável, Ética E Cidadania, 2004. Rio de Janeiro. Anais. Rio de Janeiro: Fiocruz, 2004. S. Disponível em: http://www.geocities.ws/ecdemoraes/artigobioed2 004.html. Acesso em: 27 de fevereiro de 2015.

MOREIRA, M. A. (2006). Mapas conceituais e diagramas V. Porto Alegre: Ed. do Autor.
NEHRING, C. M. et .al. As ilhas de racionalidade e o saber significativo: o ensino de ciências através de projetos. Ensaio - Pesquisa em Educação em Ciências, Belo Horizonte, v. 2, n. 1, p. 1-18, 2002.

PINHEIRO, T. C.; WESTPHAL, M.; PINHEIRO, T. F. Interdisciplinaridade nos PCN/EM/CNM\&T: bases epistemológicas e perspectivas metodológicas de alguns conceitos de interdisciplinaridade. In: IV Encontro Nacional de Pesquisa em Educação em Ciências, Florianópolis, 2007.

PIETROCOLA, M.; PINHO-ALVES,, J., PINHEIRO, T.F. Prática interdisciplinar na formação disciplinar de professores de ciências. Investigações em Ensino de Ciências, 8 (2), 131-152, 2003.

PINHEIRO, T. F. et al. Um exemplo de construção de uma ilha de racionalidade em torno da noção de energia. In: Atas do VII Encontro de Pesquisa em Ensino de Física. Florianópolis: março, 2000.

SANTOS, M. E. Encruzilhadas de mudança no limiar do século XXI: co-construção do saber científico e da cidadania via ensino CTS de ciências. In: Encontro Nacional de Pesquisa em Educação em Ciências, 2., 1999, Valinhos. Atas... Valinhos, 1999.

SCHMITZ, C. Desafio Docente: As Ilhas de Racionalidade e seus Elementos Interdisciplinares. 2004. 272f. Dissertação (mestrado em Educação Científica e Tecnológica) - CFM/CED, Universidade Federal de Santa Catarina, Florianópolis- SC, 2004.

TEIXEIRA, P. M. M. A Educação Cientifica sob a perspectiva da Pedagogia Histórico-crítica e do movimento C.T.S. no Ensino de Ciências. Revista Ciência \& Educação. Volume. 9, número. 2, 2003. p. 177-190. 